\title{
Screening of phytochemical, antimicrobial and antioxidant activity of Glycyrrhiza glabra root extract
}

Authors Info

J. Helan Chandra* and Harini Gunasekaran ${ }^{1}$,

Centre for Research, Department of Biotechnology, Jeppiaar Engineering College, Chennai-600 119, India

${ }^{*}$ Corresponding Author Email : helananand@gmail.com

Key words

Antimicrobial activity, DPPH assay, GC-MS, Glycyrrhizic acid,

Terpenoids

\section{Publication Info}

Paper received : 26.08.2016

Revised received : 15.11 .2016

Re-revised received : 01.12 .2016

Accepted:05.12.2016
ISSN: 0254-8704 (Print) ISSN: 2394-0379 (Online) CODEN: JEBIDP

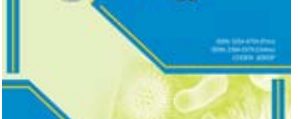

(1) 


\section{Introduction}

Glycyrrhiza glabra Linn an Indian folklore traditional medicinal plant have many therapeutic values. It is a perennial herbaceous plant that belongs to Leguminosae family. It measures about $1.5 \mathrm{~m}$ in height with wrinkled woody, brown and sweet taste roots. The leaves are unequally branched in 4-7 pairs found in subtropical and warm temperate regions. Flowers are violet colored with pods of 3-5 brown seeds (Jatav et al., 2011). G. glabra is commonly known as "liquorice" or "sweet wood". The roots and rhizomes of licorice have complex physiological properties with wide therapeutic uses. Herbs with medicinal properties are useful and effective source of treatment for various diseases (Asl and Hossein, 2008; Geetha and Roy, 2012). The main components of plant are flavonoids, saponins, essential oils and tannins. The aqueous extracts of liquorice contain $5-10 \%$ of a sweet, white, crystalline diglucuronide known as glycyrrhizin. The roots also contain $5-10 \%$ sugars (sucrose, dextrose), starch, an acid resin, malic acid and some proteinous, fatty and inorganic matters. The roots of these plants have anti-inflammatory, expectorant, carminative, hypolipidemic, antiviral, hypotensive, hepatoprotective, spasmolytic, anti-diuretic, anti-mutagenic, antipyretic, antiulcer, anxiolytic, antioxidant and aphrodisiac activities. They are useful in treating hyperdipsia, cough and bronchitis, ulceration of urinary tract, pharyngitis, epilepsy and anaemia. It is used as an expectorant and wound-healing agent in ruminants. It detoxifies and protects the liver. Medicinally, it is used internally for Addison's disease, asthma, bronchitis, peptic ulcer, arthritis and allergic complaints (Nirmala and Selvaraj, 2011; Chopra et al., 2013).

Glycyrrhizin, a triterpenoid compound, accounts for the sweet taste of G. glabra root (Yamamura et al., 1997; Kalaiarasi and Pugalendi, 2009). The yellow colour of $G$. glabra is due to the flavonoid contents like liquiritin, isoliquiritin (a chalcone) and other compounds. On acid or enzymatic hydrolysis of glycyrrhizin, it yields triterpenoid glycyrrhetinic acid and two mols of glucuronic acid. G. glabra is one of the important medicinal plants reported in the literature for its biological activities such as anti-inflammatory and expectorant, controls coughing and hormonal effects (Saxena, 2005). The extracts are often used as a flavouring agent in modern medicine (Damle, 2014). Licorice inhibits the growth and cytopathology of many unrelated DNA and RNA viruses. Glycyrrhizic acid inhibits cyclooxygenase activity and prostaglandin formation (specifically prostaglandin E2), as well as indirectly inhibiting platelet aggregation (Damle, 2014). Specifically, glycyrrhizin has antiviral activity against Herpes simplex and is capable of irreversibly inactivating the virus. Glycyrrhizin has also been shown to inhibit viral replication and infectivity of HIV (Ammar et al., 2012).

Treatment with various herbal plants and its combinations has even practiced now-a-days without knowing the active ingredients or the bioactive compounds present in it. Various solvent has been used for the preparation of crude extract of Glycyrrhiza glabra and in the current study chloroform was used due to the intermediate polarity for the better extraction. The present study focused to screen the phytochemical components present in the chloroform root extract of Glycyrrhiza glabra followed by the antioxidant and antimicrobial assay to analyze its effectiveness and also GC-MS study, to decipher the presence of various bioactive components.

\section{Materials and Methods}

Plant collection and extraction : Fresh roots of Glycyrrhiza glabra Linn commonly known as athimathuram in Tamil and Mulethi in Hindi were collected from Kancheepuram, Chennai, Tamil Nadu. They were washed and shade dried for 5 to 6 days. The dried samples were finely ground into powder. The fine powdered roots of Glycyrrhiza glabra were weighed to determine the dry weight. The extraction was carried out by Soxhlet apparatus using chloroform. About $10 \mathrm{~g}$ of dried G. glabra was dissolved in $100 \mathrm{ml}$ of chloroform and stirred using stirrer. The sample and solvent was maintained at 1:10 ratio. After extraction, the contents were filtered using Whatmann filter paper No.1. The wet weight of the sample was recorded. The filtrate was kept on a hot water bath at $75^{\circ} \mathrm{C}$ to concentrate the product by evaporating the residual solvents in the filtrate.

Characterization of chloroform root extract : The extracts were characterized by phytochemical screening, DPPH assay and GC-MS analysis followed by antimicrobial assay.

Phytochemical screening: Two grams of extract was dissolved in $20 \mathrm{ml}$ of chloroform and filtered to remove debris. The extract were qualitatively tested for various phytochemical components like alkaloids, saponins, flavanoids, tannins, Phlobotannins, terpenoids, sterols, glycosides, Cardiac Glycosides, quinines, anthroquinones, carbohydrates, proteins, Oxalates and anthocyanins (Harborne, 1998; Devmurai, 2010; Savithramma et al., 2012; Somkuwar and Kamble, 2013).

DPPH (2,2-diphenyl-1-picrylhydrazyl) assay: Antioxidant assay was carried out using ascorbic acid as standard. $I C_{50}$ value ( $50 \%$ inhibition) was calculated from the graph of inhibition percentage plotted against extract concentration (Patel and Patel, 2011).

GC-MS Analysis : Isolation of pure, pharmacologically active constituents from plants remain a long and tedious process. GCMS analysis of chloroform root extract of G. glabra were performed at SGS Private Limited, Chennai, using 5975 inert XL MSD(Agilent Technologies, CA, USA) equipped with J \&W DB$5 \mathrm{~ms}$ capillary column $($ size $=30 \mathrm{~m} \times 0.25 \mathrm{~mm}$; film thickness $=0.25$ $\mu \mathrm{m})$. The initial temperature was set at $40^{\circ} \mathrm{C}$ which increased to $150^{\circ} \mathrm{C}$ at the rate of $10^{\circ} \mathrm{C} \mathrm{min}$. At the rate of $5^{\circ} \mathrm{C} \mathrm{min}{ }^{-1}$, the temperature was again increased to $230^{\circ} \mathrm{C}$. The process continued till temperature reached $280^{\circ} \mathrm{C}$ at the rate of $20^{\circ} \mathrm{C} \mathrm{min}^{-1}$ 
which was held for $8 \mathrm{~min}$. Injector port temperature remained at $280^{\circ} \mathrm{C}$ and detector temperature was $250^{\circ} \mathrm{C}$. Helium was used as carrier gas with a flow rate of $1 \mathrm{ml} \mathrm{min}^{-1}$. The samples were injected in split mode as 110:1 and the ionization voltage was $70 \mathrm{eV}$.

Antibacterial activity by disc diffusion method : Antibacterial activities of solvent extracts of $G$. glabra were determined by disc diffusion method on Muller Hinton agar (MHA) medium. The sample concentrations were $1000 \mathrm{mg} \mathrm{ml}^{-1}, 500 \mathrm{mg} \mathrm{ml}^{-1}, 250 \mathrm{\mu g} \mathrm{ml}^{-1}$, $125 \mathrm{\mu g} \mathrm{ml}^{-1}$ and $62.5 \mathrm{\mu g} \mathrm{ml}^{-1}$. Streptomycin on MHA plates served as positive control while DMSO served as negative control. The test microorganisms were Escherichia coli and Staphylococcus aureus.

Antifungal activity by disc diffusion method : Antifungal activities of solvent extracts of $G$. glabra were determined by disc diffusion method on potato dextrose agar medium. The sample was loaded in the concentration of $1000 \mathrm{\mu g} \mathrm{ml}^{-1}, 500 \mathrm{~g} \mathrm{ml}^{-1}, 250$ $\mu \mathrm{g} \mathrm{ml}{ }^{-1}, 125 \mathrm{\mu g} \mathrm{ml}^{-1}$ and $62.5 \mathrm{\mu g} \mathrm{ml}^{-1}$ with negative control as DMSO and positive control as amphotericin $B$ on respective disc and placed on PDA plates. Candida albicans and Aspergillus niger were selected as test organisms for the study. The plates were incubated for $24 \mathrm{hrs}$ at $37^{\circ} \mathrm{C}$. Microbial growth was determined by measuring the diameter of zone of inhibition.

\section{Results and Discussion}

Ten percent (W/V) of finely powdered root of G. glabra were subjected to chloroform extraction using soxhlet apparatus in order to achieve a final concentration of $3 \mathrm{mg} \mathrm{mll}^{-1}$. Table 1 represents the presence of phytoconstituents such as alkaloids, flavonoids, saponins, carbohydrates, tannins, phlobotannins, anthraquinones, terpenoids, cardiac glycosides, glycosides, anthocyanin and sterols which was confirmed through preliminary routine qualitative analysis. Chloroform extraction yielded more components (Table 1) than earlier reported presence of steroids in ethanolic extract and presence of tannins, flavonoids, sugars in petroleum ether extracts respectively (Chopra et al., 2013). Polarity, structural stability and mass transfer parameters such as diffusibility, coefficient, molecular stability and concentration gradient might attribute to the presence of more components in chloroform extract than others (Harborne, 1998). Based on the preliminary studies, it is hypothesized that chloroform may prove to be a better solvent with respect to $G$. glabra root extract.

Free radical scavenging activity is a potent indicator for the bioactive compounds that acting as an effective phytotherapeutics. Table 2 shows the antioxidant activity of $G$. glabra root extract with $100 \mu \mathrm{g}$ and $500 \mu \mathrm{g}$ exhibiting minimal $70.33 \pm 5.67$ and maximal $87.70 \pm 4.09$ scavenging activity. Flavonoids and other phenolic compounds act as reducing agent by an effectual electron donors/hydrogen atom acceptors. Free radical centred purple coloured DPPH (2,2-diphenyl-1picrylhydrazyl) converted into yellow coloured non radical form of 1,1-diphenyl-2-picryl hydrazine when it was treated with bioactive compounds. Presence of prominent antioxidant components in the extract reported positive correlation between the extract concentration and antioxidant activity (Vaya et al., 1997; Mambro and Fonseca, 2005; Chin et al., 2007). Inhibition concentration $\left(\mathrm{IC}_{50}\right)$ of plant extract was $120.16 \mathrm{\mu g} \mathrm{ml}^{-1}$.

GC-MS analysis revealed the presence of seven metabolites such as Pyridine-3-carboxamide, oxime, N-(2trifluoromethylphenyl)-; Benzonitrile, 2-fluoro-4-(4'-propy|[1,1'bicyclohexyl]-4-yl); Benzamide, 2-bromo-N-[2-(3-fluorophenyl)-5benzoxazolyl]-; 4-Piperidylbenzilate; 3-Dibenzofuranamine; Lauric anhydride and Carbamicacid, N-(3-chloro-4-

Table 1 : Screening of phytochemicals in chloroform root extract of $G$. glabra

\begin{tabular}{lll}
\hline Phytocompounds & Test/chemical reagent & Chloroform \\
\hline Alkaloids & Mayer's test & + \\
& Dragendorf's test & + \\
Flavonoids & NaOH test & + \\
& Shinoda's test & - \\
Saponins & Foam test & + \\
& Lead acetate test & + \\
Carbohydrates & Benedict's test & - \\
& Molisch's test & + \\
Protein & Biuret test & - \\
& Ninhydrin test & - \\
Tannins & Xanthoprotein test & - \\
& Ferric chloride test & + \\
Phlobatannins & Lead acetate test & + \\
Quinones & HCl Test & + \\
& NaOH Test & + \\
Anthraquinones & HCl Test & + \\
Terpenoids & HCl Test & - \\
Glycosides & Salkowski's test & + \\
Cardiac Glycosides & Fehling's test & + \\
Sterols & Keller Kelliani's test & + \\
Coumarins & Leibermann Burchard test & + \\
Anthocyanin & NaOH and CHCl test $_{\text {Oxalate }}$ & - \\
\hline & UV fluorescent test & - \\
& NaOH test & + \\
& Ethanolic glacial acid test & - \\
\hline
\end{tabular}

Table 2 : Antioxidant activity by DPPH assay for chloroform root extract of G. glabra

\begin{tabular}{ll}
\hline Concentration $(\boldsymbol{\mu g})$ & $\%$ of antioxidant activity \\
\hline 100 & $70.33 \pm 5.67$ \\
200 & $72.83 \pm 3.54$ \\
300 & $78.53 \pm 6.07$ \\
400 & $86.3 \pm 4.51$ \\
500 & $87.70 \pm 4.09$ \\
$\mathrm{IC}_{50}$ Value & $120.16 \mu \mathrm{g} \mathrm{ml}^{-1}$ \\
\hline
\end{tabular}

Values are mean of triplicates \pm SD 
Table 3 : Phytocomponents identified in the chloroform root extract of G. glabra by GCMS

\begin{tabular}{lll}
\hline Constituents name & Retention time factor & Area \% \\
\hline Pyridine-3-carboxamide, oxime, N-( 2-trifluoromethylphenyl)- & 24.635 & 29.80 \\
Benzonitrile,2-fluoro-4-(4'-propyl[1,1'-bicyclohexyl]-4-yl)- & 24.829 & 5.95 \\
Benzamide, 2-bromo-N-[2-(3-fluorophenyl)-5-benzoxazolyl]- & 27.483 & 33.48 \\
4-Piperidylbenzilate & 27.689 & 19.09 \\
3-Dibenzofuranamine & 27.753 & 5.15 \\
Lauric anhydride & 27.788 & 1.08 \\
Carbamicacid,N-(3-chloro-4-methoxyphenyl)-glycidyl ester & 27.894 & 5.44 \\
\hline
\end{tabular}

Table 4 : Antibacterial activity of chloroform root extract of G. glabra

\begin{tabular}{|c|c|c|c|c|c|c|c|}
\hline \multirow[t]{2}{*}{ Microorganisms } & \multicolumn{7}{|c|}{ Zone of Inhibition (mm) } \\
\hline & $1000 \mu \mathrm{g}$ & $500 \mu g$ & $250 \mu \mathrm{g}$ & $125 \mu \mathrm{g}$ & $62.5 \mu \mathrm{g}$ & DMSO & Streptomycin $(10 \mu \mathrm{g})$ \\
\hline \multicolumn{8}{|l|}{ Antibacterial activity } \\
\hline Escherichia coli & $8.00 \pm 1.50$ & $7.00 \pm 1.35$ & $7.66 \pm 1.15$ & - & - & - & $8.00 \pm 1.00$ \\
\hline Staphylococcus aureus & $17.83 \pm 1.75$ & $22.50 \pm 1.32$ & $23.66 \pm 1.15$ & $16.83 \pm 1.60$ & $19.33 \pm 1.52$ & & $15.66 \pm 3.05$ \\
\hline \multicolumn{8}{|c|}{ Values are mean of triplicates \pm SD } \\
\hline \multirow[t]{2}{*}{ Microorganisms } & \multicolumn{7}{|c|}{ Zone of Inhibition (mm) } \\
\hline & $1000 \mu \mathrm{g}$ & $500 \mu \mathrm{g}$ & $250 \mu \mathrm{g}$ & $125 \mu \mathrm{g}$ & $62.5 \mu \mathrm{g}$ & DMSO & Amphotericin B $(20 \mu \mathrm{g})$ \\
\hline \multicolumn{8}{|l|}{ Antifungal activity } \\
\hline Candida albicans & $11.00 \pm 1.00$ & $15.33 \pm 1.51$ & $13.00 \pm 1.00$ & $10.33 \pm 1.08$ & $11.33 \pm 1.51$ & - & $4.66 \pm 1.52$ \\
\hline Aspergillus niger & $10.00 \pm 1.00$ & $7.33 \pm 1.52$ & $5.66 \pm 1.15$ & - & - & - & $9.33 \pm 1.51$ \\
\hline
\end{tabular}

Values are mean of triplicates \pm SD

methoxyphenyl), glycidyl ester. Major components present in the chloroform extract were Pyridine-3-carboxamide, oxime, N-(2trifluoromethylphenyl)-; Benzamide, 2-bromo-N-[2-(3fluorophenyl)-5-benzoxazolyl]-and 4-Piperidyl benzilate (Table 3).

Among these seven compounds Carbamicacid,N-(3chloro-4-methoxyphenyl)-,glycidyl ester was abundant present in the chloroform root extract of $G$. glabra. Whereas methanolic root extract of G. Glabra showed the presence of 3-Pyridinol; $4 \mathrm{H}-$ Pyran-4-one, 2,3-dihydro-3,5-dihydroxy- 6-methyl-; Benzofuran; Isosorbide; 2-Methoxy-4-vinylphenol; Methylparaben; D-Allose; Octanal,2-(phenylmethylene)-; Hexadecanoic acid, methyl ester; n-Hexadecanoic acid and Dibutyl phthalate (Rattan et al., 2014).

The extracts were tested for their antibacterial and antifungal activity using disc diffusion method and the zone of inhibition is shown in Table 4 and 5 respectively. The maximum zone of inhibition in the chloroform extract was observed as $23 \pm 1.32 \mathrm{~mm}$ at concentration of $250 \mathrm{\mu gml}^{-1}$ with $\mathrm{S}$. aureus. The best result was shown in $C$. albicans with chloroform extract of $500 \mathrm{mgml}^{-1}$. The maximum zone of inhibition was found to be
$15.33 \mathrm{~mm}$ for $C$. albicans when compared to $A$. niger. Observed results exhibited the effective antibacterial and antifungal activity of the root extract of $G$. glabra which might be due the presence of phytocomponents. Available literatures also advocate that the presence of phytoconstituents in the plant extract exhibited antimicrobial, antimycobacterial and antifungal activity and also it could act as phytotherapeutical component. (Gupta et al., 2008; Sadul et al., 2012; Sharma and Agarwal, 2013; Ates and Erdourul, 2003; Sedighinia et al., 2012; Helan and Suhashini, 2015).

Confirmed availability of seven bioactive compounds by GC-MS in the chloroform root extract could be responsible for the antimicrobial activity. Inhibition in the bacterial test might be due to the presence of pyridine-3-carboxamide oxime n-(2-trifluoromethyl phenyl)- in the extract has 2 hydrogen donor bonds and 6 hydrogen acceptor bonds which was categorized as a strong antibacterial activity with respect to $S$. aureus. Higher inhibition was found at $250 \mathrm{\mu g} \mathrm{ml}^{-1}$ rather than $1000 \mathrm{~g} \mathrm{~m}^{-1}$, where protein would have been modulated at higher concentration because of MgrA protein present in S. aureus (NCBI, 2016a). Inhibition in bacterial activity might also be due to lipoteichoic acid which is present in cell wall 
polymer of Gram positive bacteria where Pyridine-3-carboxamide oxime n-(2-trifluoromethyl phenyl)- blocks phosphatidylglycerol binding to $L$ taS, a protein present in virulent strains of $S$. aureus (NCBI, 2016b). The results of antimicrobial and antifungal study revealed the efficient activity of crude extract which might be due to the presence of soluble bioactive components and were confirmed by phytochemical analysis, DPPH assay and GC-MS analysis. Thus, the roots of Glycyrrhiza glabra can be used for the extraction of phytotherapeutics. Current study is the first of its kind but it has to be warranted and validated by further experimental methodologies.

\section{Acknowledgments}

The authors acknowledge Department of Biotechnology, Jeppiaar Engineering College and Rajkeerth Aromatics and Biotech Pvt. Ltd., for providing all the necessary equipments, instrumentations and details for completion of the project in time.

\section{References}

Ammar, N.M., S.S. El-Hawary, A.A. El-anssary, N. Othman, M. Galal and A.H. El-Desoky: Phytochemical and clinical studies of the bioactive extract of Glycyrrhiza glabra L. Family Leguminosae. Int. J. Phytomed., 4, 429-436 (2012).

Asl, M.N. and Z.H. Hossein: Review of pharmacology effect of Glycyrrhiza sp. and its bioactive compounds. Phytother. Res., 22, 709-724 (2008).

Ates, D.A. and Z.T. Erdourul: Antimicrobial activities of various medicinal and commercial plant extracts. Turk. J. Bio., 27, 157-162 (2003).

Chin, Y.W., H.A. Jung, Y. Liu, B.N. Su, J.A. Castoro, W.J. Keller, M.A. Pereira and A.D. Kinghorn: Antioxidant constituents of the roots and stolons of licorice (Glycyrrhiza glabra). J. Agri. Food. Chem., 55, 4691-4696 (2007).

Chopra, P.K.P.G., B.D. Saraf, F. Inam and S. Deo:Anti-microbial and antioxidant activity of methanol extract roots of $\mathrm{G}$. glabra and HPLC analysis. Int. J. Pharm. Sci., 5, 157-160 (2013).

Damle, M.: Glycyrrhiza glabra (Liquorice) - a potent medicinal herb. Int. J. Herb. Med., 2, 132-136 (2014).

Devmurai V.P.: Phytochemical screening study and antibacterial evaluation of Symplocos racemosa Roxb. Arch Appl Sci Res., 2, 354-359 (2010).

Geetha, R.V. and A. Roy: In vitro evaluation of anti bacterial activity of ethanolic root extract of Glycyrrhiza glabra on oral microbes. Int. J. Drug Dev. Res., 4,161-165 (2012).

Gupta, V.K., F. Atiya, F. Uzma, S.N. Arvind, S. Karuna, J.K. Kumar, R. Neha, L. Suaib, S.S. Brijesh, S. Dharmendra, M.P. Darokar and P.S. Suman: Antimicrobial potential of Glycyrrhiza glabra roots. J. Ethnopharmacol., 116, 377-380 (2008).

Harborne, J.B.: Phytochemical methods: A guide to modern techniques of plant analysis. $3^{\text {rd }}$ Edn., Chapman and Hall, London., pp.
182-190 (1998).

Helan, J.C. and R. Suhashini: In vitro screening of antibacterial and antioxidant activity and In silico analysis of three sided Cissus quadrangularis. Int. J. Pharm. Bio. Sci., 6, 657-665 (2015).

Jatav, V.S., S.K. Singh, P. Khatri and A.K. Sharma: Recent pharmacological trends of Glycyrrhiza glabra L. Int. J Pharmac. Fron. Res., 1,170-185(2011).

Kalaiarasi, P. and K.V. Pugalendi: Antihyperglycemic effect on $18 \beta$ -glycyrrhetinic acid, aglycone of glycyrrhizin on streptozotocindiabetic rats. Eur. J. Pharmacol., 606, 269-273 (2009).

Mambro, D.V.M. and M.J. Fonseca: Assays of physical stability and antioxidant activities of a topical formulation added with different plant extract. J. Pharma. Biomed. Anal., 37, 287-295 (2005).

National Centre for Biotechnology Information (NCBI): Pubchem bioassay database. AID: 602314, $3^{\text {rd }}$ June (2016a).

National Centre for Biotechnology Information (NCBI): Pubchem bioassay database. AID: 720641, $3^{\text {rd }}$ June (2016b).

Nirmala, P. and T. Selvaraj: Anti-inflammatory and antibacterial activity of G. glabra. J. Agricul. Technol., 7, 815-823 (2011).

Patel R.M. and N.J. Patel: In vitro antioxidant activity of coumarin compounds by DPPH, super oxide and nitric oxide free radical scavenging methods. J.Adva. Phar. Educ. Res., 1, 68 (2011)

Rattan S., G. Satpathy and K.R. Gupta: Formulation of biscuits with Glycyrrhiza glabra root extract, Ocimum sanctum and Pimpinella anisum extract added as a nutraceutical. J. Pharma. Phytochem., 3, 10-16 (2014).

Sadul, R.R., R.G. Milind and N.K. Bipinraj: Comparative of antimicrobial activity and phytochemical screening of aqueous and alcoholic leaf extract of Ocimum sanctam and $E$. coli (faecal indicator of water pollution). J. Environ. Res. Develop., 7, 312-320 (2012).

Savithramma, N., S. Ankanna, M.L. Rao and J. Saradavathi: Studies on antimicrobial efficacy of miedicinal tuberous shrub Talinum cuneifolium. J. Environ. Biol., 33, 775-780 (2012).

Saxena, S.: Glycyrrhiza glabra: Medicine over the millennium. Nat. Prod. Radi., 4, 358-367 (2005).

Sedighinia, F., A. Aafipour and S.S. Afshar: Antibacterial activity of G. glabra against the oral pathogen and invitro study. J. Phytomed., 2, 118-124 (2012).

Sharma, V. and R.C. Agarwal: Glycyrrhiza glabra-A plant for the review. Mintage J. Pharmac. Medical. Sci., 2,15-20 (2013).

Somkuwar, D.O. and V.A. Kamble: Phytochemical screening of ethanolic extracts of stem, leaves, flower and seed kernel of Mangifera indica L. Int. J. Pharm. Biol. Sci., 4, 383-389 (2013).

Vaya, J., P.A. Belinky and M. Aviram: Antioxidant constituents from licorice roots: isolation, structure elucidation and antioxidative capacity toward LDL oxidation. Free Radic. Biol. Med., 23, 302-313 (1997).

Yamamura, Y., H. Kotaki, N. Tanaka, T. Aikawa, Y. Sawada and T. Iga: The pharmacokinetics of glycyrrhizin and its restorative effect on hepatic function in patients with chronic hepatitis and in chronically carbon-tetrachloride-intoxicated rats. Biopharm. Drug Dispos., 18, 717-725(1997). 